\title{
Physician burnout
}

\author{
Shannon M. Ruzycki MD, Jane B. Lemaire MD
}

Cite as: CMAJ 2018 January 15;190:E53. doi: 10.1503/cmaj.170827

CMAJ Podcasts: author interview at https://soundcloud.com/cmajpodcasts/170827-five

1

Burnout is a work-related syndrome that occurs in occupations where others' needs come first, and where there are high demands, few resources and a disconnect between workers' expectations and experiences ${ }^{1}$

Burnout is characterized by emotional exhaustion, depersonalization or feelings of detachment and cynicism toward people and work, and a reduced sense of accomplishment. ${ }^{1}$ In contrast, the absence of burnout may be an indicator of physician wellness, which translates into engagement and satisfaction with work, and a sense of thriving in physical, emotional and social health., ${ }^{1,2}$

2

Many physicians experience symptoms of burnout, which often begin in medical school and increase during residency training ${ }^{2-5}$

Risk factors for burnout include organizational factors such as workload and lack of autonomy, and personal factors such as female gender. ${ }^{1-5}$ Resources for physicians experiencing burnout are shown in Box 1.

\section{3}

Physicians with burnout experience its effects in both their professional and personal lives ${ }^{2-5}$

Burnout is associated with depression, suicidal ideation and substance abuse, as well as unprofessional behaviour, reduction in work hours and medical errors. ${ }^{2-5}$

\section{4}

Burnout is difficult to recognize and address in oneself and

\section{in colleagues}

Few physicians who self-identify as burnt out seek outside help, and physicians are cautious about reporting distressed colleagues. ${ }^{2}$ This is in part owing to perceived stigma, denial and avoidance as coping strategies, and concerns about licensing. ${ }^{2}$

Strategies to improve physician wellness should target organizations as well as individual physicians ${ }^{3-5}$

Two recent meta-analyses show that organization-directed interventions, such as increased autonomy and scheduling changes, are associated with a moderate but substantial reduction in physician burnout., ${ }^{4,5}$ These interventions may be more effective than physician-directed ones, such as mindfulness training and stress-management techniques, although combined approaches are likely the most successful. ${ }^{4,5}$

\section{Box 1: Resources for physicians, residents and} medical students experiencing burnout*

\section{Organization}

Contact

Alberta Medical Association Physician and Family Support Program $\dagger$

Physician Health Program of British Columbia

Doctors Manitoba Health and Wellness Program

New Brunswick Medical Society Physician Health Program

Newfoundland and Labrador Medical Association Physician Care Network

Doctors Nova Scotia Professional Support Program

Ontario Medical Association

Physician Health Program

Quebec Physicians Health Program

Physician Support Program of Prince Edward Island

Saskatchewan Medical Association Physician Health Program

${ }^{*}$ Other resources are available through the provincial professional associations of resident physicians and the offices of learner wellness within Canadian faculties of medicine.

tThere are no organizations for Nunavut, the Northwest Territories or Yukon, but Alberta has an agreement with the Northwest Territories to provide some support.

\section{References}

1. Maslach C, Leiter MP. Understanding the burnout experience: recent research and its implications for psychiatry. World Psychiatry 2016;15:103-11.

2. Wallace JE, Lemaire JB, Ghali WA. Physician wellness: a missing quality indicator. Lancet 2009;374:1714-21.

3. Dyrbye L, Shanafelt T. A narrative review on burnout experienced by medical students and residents. Med Educ 2016;50:132-49.

4. West CP, Dyrbye LN, Erwin PJ, et al. Interventions to prevent and reduce physician burnout: a systematic review and meta-analysis. Lancet 2016;388:2272-81.

5. Panagioti M, Panagopoulou E, Bower P, et al. Controlled interventions to reduce burnout in physicians: a systematic review and meta-analysis. JAMA Intern Med 2017;177:195-205.

\section{Competing interests: None declared.}

This article has been peer reviewed.
Affiliations: Department of Medicine (Ruzycki, Lemaire), Cumming School of Medicine; Ward of the 21st Century Research and Innovation Centre (Lemaire), University of Calgary, Calgary, Alta.
Correspondence to: Shannon Ruzycki, sarro@ualberta.ca 